\title{
Echocardiographic pattern of right atrial tumour motion
}

\author{
Zia Q. Farooki, Edward W. Green, and Eduardo Arciniegas \\ From the Section of Cardiology, Children's Hospital of Michigan and Department of Pediatrics, Wayne State \\ University, Detroit, Michigan, U.S.A.
}

Propagation of Wilm's tumour to the right atrium was diagnosed by echocardiography. The tumour prolapsed into the right ventricle during each atrial systole. The presence of the tumour and its motion were confirmed by cardiac catheterization, cineangiography, and surgical exploration. Successful resection of the tumour was accomplished. Echocurdiography was helpful in detecting the presence of the right atrial tumour and accurately reflected the pattern of its atrioventricular motion.

Echocardiography is of established value in the diagnosis of atrial and ventricular cardiac tumours. We wish to report the ultrasonic pattern of a right atrial tumour which prolapsed into the right ventricular outflow tract during each atrial systole. We could find only one report of similar echocardiographic findings in the paediatric agegroup (Zajtchuk et al., 1975).

\section{Case report}

A $5 \frac{1}{2}$-year-old White girl underwent successful removal of Wilm's tumour of the left kidney in November 1974. While on chemotherapy and radiation treatment, a heart murmur was first heard in May 1975. She was referred to us in June 1975. The physical examination showed prominent ' $a$ ' waves in the jugular pulses. The praecordium was hyperactive along the left lower sternal border. The first and the second heart sounds were normal. A soft third heart sound was present at the apex and along the lower left sternal border. A grade 2/6, short, early systolic murmur was present along the left sternal border, and radiated toward the pulmonary area. A rough, low pitched, presystolic murmur was present over the left lower sternal border. The liver edge was palpable $6 \mathrm{~cm}$ below the right costal margin, and no presystolic pulsations were detectable.

Chest $x$-ray examination showed mild cardiac enlargement and two coin shaped densities in the left lung.

An electrocardiogram indicated right atrial enlargement and right bundle-branch block pattern.

\section{Echocardiography}

Ultrasonic examination (Ekoline 20, Cambridge strip chart recorder and 3.5 Megahertz transducer) was diagnostic of a large right atrial tumour, with phasic prolapse into the right ventricular cavity.

The ultrasonic transducer was held in the fourth left intercostal space, about $2 \mathrm{~cm}$ lateral to the sternal edge, and the beam was directed inferiorly, leftward, and laterally to record the ventricular septum (VS). In this position a dense layer of echoes was recorded in the right ventricular cavity during right atrial systole (Fig. 1). The beam was then directed medially, rightward, and inferiorly to record the anterior tricuspid leaflet (ATL). In this position, the abnormal, dense layer of echoes was visible throughout the cardiac cycle. During ventricular systole these echoes were seen posterior to the anterior tricuspid leaflet in the right atrial cavity. As the tricuspid valve opened, these tumour echoes prolapsed anteriorly through the tricuspid orifice. The EF slope of the anterior tricuspid leaflet was masked by the tumour echoes.

The ventricular septal motion was flat or type B (Fig. 2A). There were tumour echoes in the right ventricular cavity during ventricular presystole. The left ventricular cavity was clear of any abnormal echoes. Ultrasonic scanning of the aortic root (Fig. 2B) showed that the left atrium and the aorta were normal. Faint but definite tumour echoes were seen in the right ventricular outflow tract during right ventricular presystole.

\section{Course}

Cardiac catheterization and biplane cineangiography confirmed the presence of a large right atrial tumour which prolapsed through the tricuspid orifice into the right ventricle and up to the under surface of the pulmonary valve during atrial systole. The tumour was completely contained in the atrial cavity during right ventricular systole. The inferior vena cava was obstructed at the level of the right kidney, and venous drainage 


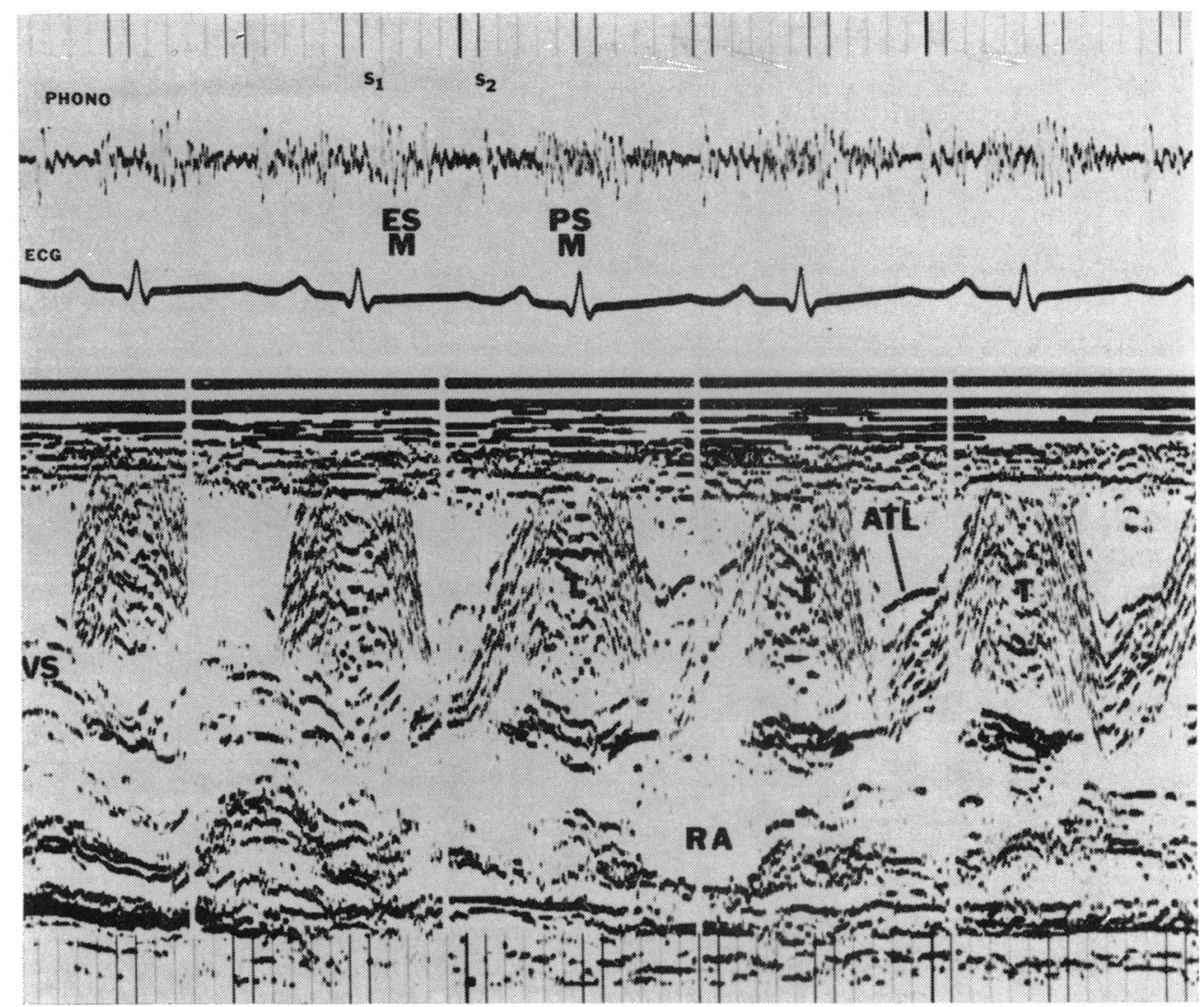

FIG. 1 Echocardiogram represents a scan of right atrial region. Left side of scan depicts ventricular septum (VS). Then transducer is rotated towards tricuspid region (right side). $R A$, right atrium; $T$, tumour; $A T L$, anterior tricuspid leaflet; phono, phonocardiogram recorded along left lower sternal edge; $S_{1}$, first heart sound; $S_{2}$, second heart sound; ESM, ejection systolic murmur; PSM, presystolic murmur, ECG, electrocardiogram.

occurred via the Batson's paravertebral plexus into the azygos and the hemiazygos systems.

Under cardiopulmonary bypass, simultaneous abdominal and cardiac exploration confirmed the clinical diagnosis of intravascular propagation of Wilm's tumour to the right heart. Successful resection of this tumour thrombus was accomplished. The histopathological diagnosis was that of highly malignant nephroblastoma.

The immediate postoperative course was uneventful. Echocardiographic examination (Fig. 3), one week after operation, showed that the tumour echoes were no longer present in the right atrium, right ventricle, and right ventricular outflow tract. The motion of the ventricular septum was normal. The patient was clinically well three months after the operation.

\section{Discussion}

Echocardiographic diagnosis of right atrial tumour was made easier by the available history of surgical resection of nephroblastoma six months previously. The echocardiogram was accurate in depicting tumour movement during the cardiac cycle. This ultrasonic study showed that the primary location of the tumour was in the right atrial cavity. Each atrial contraction forced the tumour mass through the tricuspid orifice into the right ventricular outflow tract. This resulted in the presystolic murmur because of the obstruction at the level of the tricuspid valve.

Few reports are available regarding the echocardiographic features of right atrial tumours (Zajtchuk et al., 1975; Harbold and Gau, 1973; Farooki, Henry, and Green, 1975). Approximately six cases of propagation of Wilm's tumour to the right heart have been reported in the English language (Osler, 1879; Anselmi et al., 1970; Edwards, 1972; Murphy et al., 1973; Utley et al., 1973; 


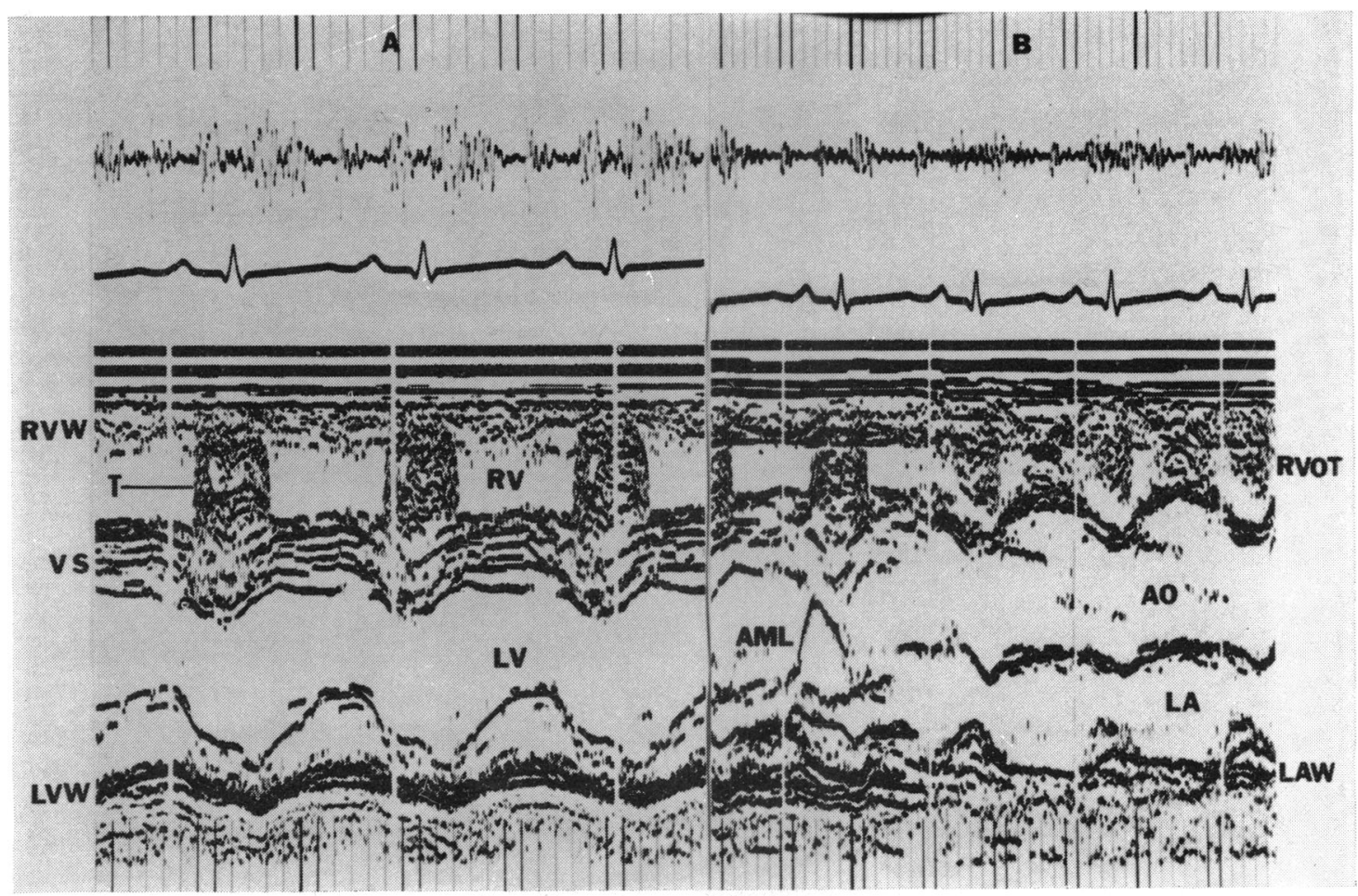

FIG. 2 Echocardiogram represents scan from left ventricular apex to aortic root. (A) RVW, right ventricular wall; $V S$, ventricular septum; $L V W$, left ventricular wall; $R V$, right ventricle; $L V$, left ventricle; $T$, tumour echoes. (B) $A M L$, anterior mitral leaflet; $R V O T$, right ventricular outflow tract; Ao, aorta; $L A$, left atrium; $L A W$, left atrial wall.

Farooki et al., 1975), and successful removal of the tumour has been accomplished previously (Murphy et al., 1973; Utley et al., 1973).

Echocardiography, as a screening procedure, is recommended for all cases of Wilm's tumour.

The authors are indebted to Dr. Barbara Cushing fer referring this patient to us. 


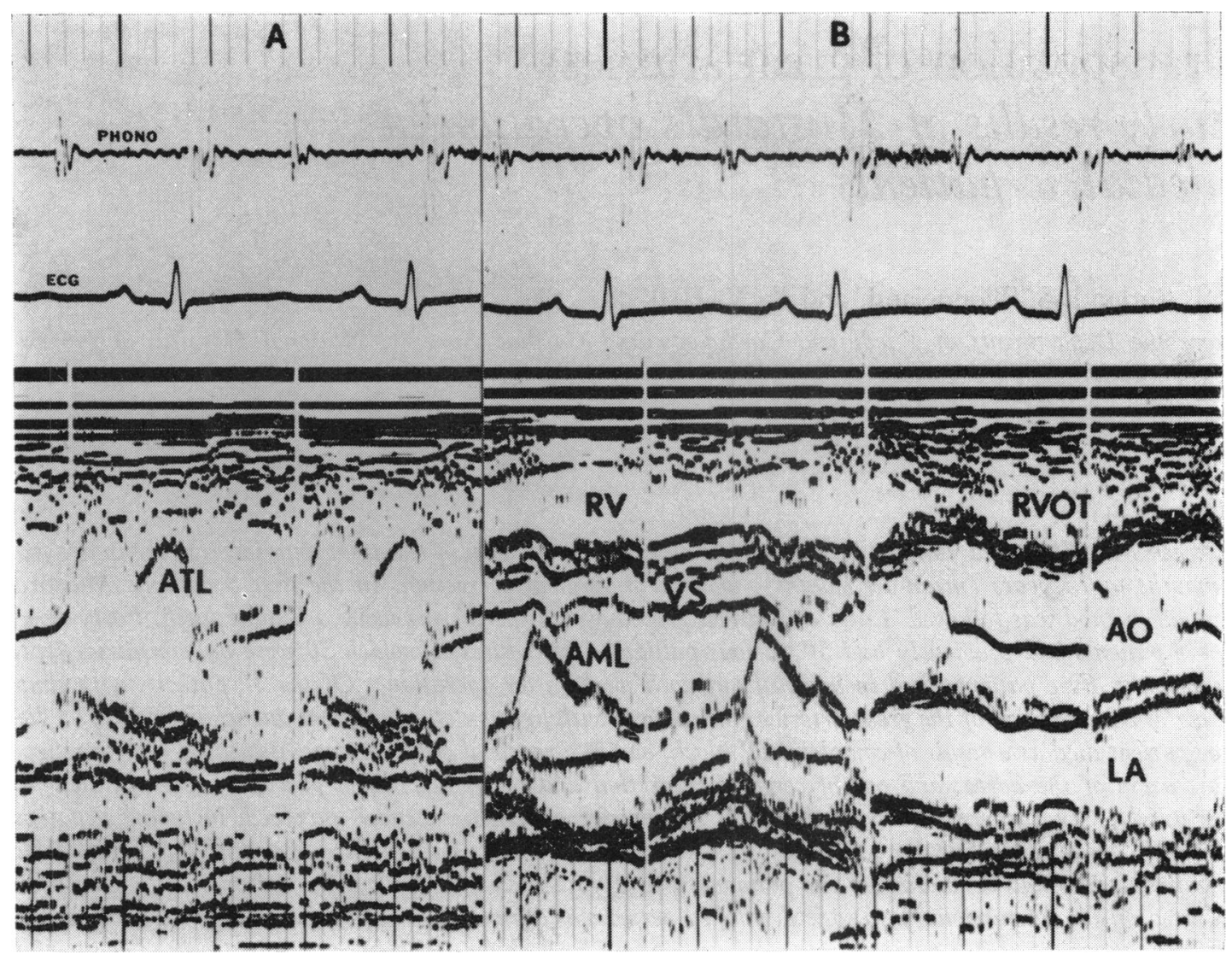

FIG. 3 Echocardiogram recorded one week after operation. Abbreviations as in Fig. 1 and 2. No tumsur echoes are seen.

Echocardiographic diagnosis of right atrial extension of Wilm's tumor. American fournal of Cardiology, 36, 363.

Harbold, N. B., and Gau, G. T. (1973). Echocardiographic diagnosis of right atrial myxoma. Mayo Clinic Proceedings, 48, 284.

Murphy, D. A., Rabinovitch, H., Chevalier, L., and Virmani, S. (1973). Wilms tumor in right atrium. American Fournal of Diseases of Children, 126, 210.

Osler, W. M. (1879). Two cases of striated myo-sarcoma of the kidney. Fournal of Anatomy and Physiology, 14, 229.

Utley, J. R., Mobin-Uddin, K., Seznitz, R. H., Belin, R. P., and Utley, J. F. (1973). Acute obstruction of tricuspid valve by Wilm's tumor. Fournal of Thoracic and Cardiovascular Surgery, 66, 626.

Zajtchuk, R., Fitterer, J. D., Strevey, T. E., and Nelson, W. P. (1975). Bilateral atrial myxomas. Preoperative diagnosis and successful removal. fournal of Thoracic and Cardiovassular Surgery, 69, 291.

Requests for reprints to Dr. Zia Q. Farooki, Section of Cardiology, Children's Hospital of Michigan, 3901 Beaubien Street, Detroit, Michigan 48201, U.S.A. 